\title{
Balloon dilatation of the Eustachian tube for obstructive Eustachian tube dysfunction in adults
}

DOI:

10.1002/14651858.CD013429

Document Version

Final published version

Link to publication record in Manchester Research Explorer

\section{Citation for published version (APA):}

Patel, A., Smith, M. E., Norman, G., Llewellyn, A., \& Tysome, J. R. (2019). Balloon dilatation of the Eustachian tube for obstructive Eustachian tube dysfunction in adults: Protocol information. Cochrane Database of Systemic Reviews. https://doi.org/10.1002/14651858.CD013429

\section{Published in:}

Cochrane Database of Systemic Reviews

\section{Citing this paper}

Please note that where the full-text provided on Manchester Research Explorer is the Author Accepted Manuscript or Proof version this may differ from the final Published version. If citing, it is advised that you check and use the publisher's definitive version.

\section{General rights}

Copyright and moral rights for the publications made accessible in the Research Explorer are retained by the authors and/or other copyright owners and it is a condition of accessing publications that users recognise and abide by the legal requirements associated with these rights.

\section{Takedown policy}

If you believe that this document breaches copyright please refer to the University of Manchester's Takedown Procedures [http://man.ac.uk/04Y6Bo] or contact uml.scholarlycommunications@manchester.ac.uk providing relevant details, so we can investigate your claim.

\section{OPEN ACCESS}




\section{Balloon dilatation of the Eustachian tube for obstructive Eustachian tube dysfunction in adults (Protocol)}

Patel A, Smith ME, Norman G, Llewellyn A, Tysome JR

Patel A, Smith ME, Norman G, Llewellyn A, Tysome JR.

Balloon dilatation of the Eustachian tube for obstructive Eustachian tube dysfunction in adults.

Cochrane Database of Systematic Reviews 2019, Issue 9. Art. No.: CD013429.

DOI: 10.1002/14651858.CD013429.

www.cochranelibrary.com 
TABLE OF CONTENTS

HEADER 1

ABSTRACT

BACKGROUND

OBJECTIVES

METHODS

ACKNOWLEDGEMENTS

REFERENCES

APPENDICES

CONTRIBUTIONS OF AUTHORS

DECLARATIONS OF INTEREST

SOURCES OF SUPPORT 
[Intervention Protocol]

\section{Balloon dilatation of the Eustachian tube for obstructive Eustachian tube dysfunction in adults}

Anant Patel ${ }^{1}$, Matthew E Smith², Gill Norman³ , Alexis Llewellyn ${ }^{4}$, James R Tysome 5

1Department of ENT Surgery, Norfolk \& Norwich University Hospital, Norwich, UK. 2Department of ENT Surgery, Cambridge University Hospitals NHS Foundation Trust, Cambridge, UK. ${ }^{3}$ Division of Nursing, Midwifery and Social Work, School of Health Sciences, Faculty of Biology, Medicine and Health, University of Manchester, Manchester Academic Health Science Centre, Manchester, UK. ${ }^{4}$ Centre for Reviews and Dissemination, University of York, York, UK. ${ }^{5}$ Cambridge University Hospitals NHS Foundation Trust, Cambridge, UK

Contact address: Anant Patel, Department of ENT Surgery, Norfolk \& Norwich University Hospital, Conley Lane, Norwich, NR4 7UY, UK. anantpatel86@gmail.com.

Editorial group: Cochrane ENT Group

Publication status and date: New, published in Issue 9, 2019.

Citation: Patel A, Smith ME, Norman G, Llewellyn A, Tysome JR. Balloon dilatation of the Eustachian tube for obstructive Eustachian tube dysfunction in adults. Cochrane Database of Systematic Reviews 2019, Issue 9. Art. No.: CD013429. DOI: 10.1002/14651858.CD013429.

Copyright @ 2019 The Cochrane Collaboration. Published by John Wiley \& Sons, Ltd.

\section{A B S T R A C T}

This is a protocol for a Cochrane Review (Intervention). The objectives are as follows:

To evaluate the effects of balloon dilatation of the Eustachian tube in adults with obstructive Eustachian tube dysfunction. 


\section{B A C K G R O U N D}

\section{Description of the condition}

The Eustachian tube is a narrow tube approximately $35 \mathrm{~mm}$ long in adults, which extends from the back of the nose (nasopharynx) to the middle ear. The two-thirds closest to the nasopharyngeal opening is made from cartilage and other soft tissue, whilst the third closest to the middle ear is a bony tube within the temporal bone. The Eustachian tube performs three primary functions: 1 ) pressure equalisation and ventilation of the middle ear; 2 ) mucociliary clearance of secretions from the middle ear; and 3) protection of the middle ear from sounds and from pathogens or secretions from the nasopharynx (Bluestone 2005; Sade 1997). To fulfil these functions the Eustachian tube is normally closed, but it opens momentarily either actively during swallowing or passively due to a pressure gradient (Alper 2012; Poe 2000).

The most important function of the Eustachian tube is maintenance of an ambient middle ear air pressure to facilitate sound transmission from the ear drum to the middle ear. Two processes act on the middle ear gas pressure. The first is gas exchange across the middle ear cleft cell lining, which tends to create a negative pressure (Adil 2014; Pau 2009); the second process is Eustachian tube opening, which permits intermittent equalisation of middle ear pressure with atmospheric pressure via the nose.

Eustachian tube dysfunction is usually defined by symptoms and signs of pressure dysregulation in the middle ear, resulting in symptoms of ear fullness, popping and crackling sounds, ear discomfort, muffled hearing and tinnitus (McCoul 2012b; Schilder 2015). It can also be a mechanism for middle ear disease and is associated with tympanic membrane retraction, otitis media with effusion ('glue ear') and chronic otitis media (Bluestone 2005). Eustachian tube dysfunction and these related middle ear conditions account for over two million adult hospital visits per annum in the USA (Vila 2017), and prevalence in the UK was previously reported to be $0.9 \%$ (Browning 1992).

An expert consensus group has agreed on definitions for acute and chronic Eustachian tube dysfunction, with acute dysfunction relates to transient symptoms and signs for up to three months, and chronic dysfunction relates to symptoms and signs for more than three months (Schilder 2015). The consensus group further categorised Eustachian tube dysfunction into dilatory, baro-challenge-induced and patulous dysfunction. The term 'obstructive' Eustachian tube dysfunction is used widely in clinical practice and in the medical literature, and refers to dilatory Eustachian tube dysfunction, which indicates a problem with the ventilatory function of the Eustachian tube in conditions of normal atmospheric pressure. Dilatory dysfunction may be due to functional obstruction, dynamic dysfunction (e.g. muscular failure) or anatomic obstruction (Bluestone 2005; Doyle 2013; Schilder 2015).

Patient-reported outcome measures (PROMs) for Eustachian tube dysfunction include the Eustachian Tube Dysfunction Questionnaire (ETDQ-7) (McCoul 2012b) and the Eustachian Tube Score (ETS) and its extension (ETS-7), which combine subjective patient-reported symptom scores with clinical findings. A retracted tympanic membrane on examination of the ear, or type B or C tympanogram trace indicating abnormal middle ear function (Jerger 1972), are commonly used as 'indicators' of Eustachian tube dysfunction both in clinical practice and research studies. More complex tests of Eustachian tube function are primarily used in research, the most common of these being tubomanometry and sonotubometry, which respectively measure pressure and sound transmitted down the Eustachian tube as it opens during swallowing (Smith 2015).

The most significant issue relating to research in this field is the lack of a gold-standard reference test against which to measure the accuracy of proposed diagnostic tests for Eustachian tube function. In clinical practice, most diagnoses are made based on patient-reported symptoms combined with otoscopic and tympanometric findings. However, these do not correlate well with objective measures of Eustachian tube opening, that is sonotubometry and tubomanometry (Smith 2018). PROMs therefore have poor diagnostic value and are perhaps best used only when monitoring symptoms or response to treatment. Whilst an agreed approach to the diagnosis of Eustachian tube dysfunction is still lacking, a combination of objective measures of Eustachian tube opening (tympanometry, sonotubometry and tubomanometry) and clinical opinion is currently advised (Smith 2018).

Symptoms attributed to chronic Eustachian tube dysfunction are often treated conservatively. Interventions aiming to improve the underlying Eustachian tube dysfunction, or to provide an alternative method of middle ear ventilation, include non-surgical and surgical approaches. Non-surgical interventions typically used as firstline treatments include pharmacological treatments such as nasal steroids and decongestants, and manual autoinflation devices that aim to equalise middle ear pressure (Perera 2013). Surgical interventions may require general anaesthesia and include myringotomy with ventilation tube (grommet) insertion, laser Eustachian tuboplasty and Eustachian tube balloon dilatation. A 2014 systematic review found limited evidence and could not draw conclusions regarding the effectiveness of any of the interventions for adult Eustachian tube dysfunction (Llewellyn 2014).

\section{Description of the intervention}

Balloon Eustachian tuboplasty (BET) is a method of dilating the cartilaginous Eustachian tube using a catheter-mounted balloon. A number of BET devices are available, with variable diameters and length. BET is typically performed under a general anaesthetic and transnasally, under endoscopic guidance using an angled rigid endoscope. The balloon catheter is inserted into the nasopharyngeal opening of the Eustachian tube using an angled introducer and gently advanced until the balloon is fully inserted at approximately $20 \mathrm{~mm}$, where there is a defined stop point that prevents the balloon being over-inserted into the bony Eustachian tube. This is where an aberrant course or dehiscent carotid might be present and at risk during the procedure. Once positioning is confirmed, a manually operated syringe allows inflation of the balloon to a pressure of around 10 atmospheres. At this pressure, the balloon adopts a pre-defined size and is relatively rigid. The balloon is left in situ for one to two minutes before being deflated and removed. This procedure takes between three and five minutes per Eustachian tube.

Some groups have used BET in combination with another surgical procedure including both sinonasal and otological surgery (Catalano 2012). Other co-interventions, such as septoplasty (Catalano 2012), can be used to improve access to the nasopharynx and Eustachian tube. It is unclear what effect, if any, these interventions may have on Eustachian tube dysfunction or associated symptoms. 
Adverse effects of BET have been reported in the literature, the majority of which occur at the time of surgery and are mild and self-limiting, such as minor bleeding from the site of tuboplasty or emphysema that resolves within a few days (Poe 2011b; Schroder 2015). Other early adverse effects are a temporary increase in rhinitic symptoms (Gürtler 2015) and tinnitus (Schroder 2015). Complications requiring a return to theatre for a revision procedure have been reported (McCoul 2012c), as have early adverse effects such as a temporary increase in rhinitic symptoms. Late complications have not been widely reported (Huisman 2018; Randrup 2015). We have not found reports of carotid rupture.

\section{How the intervention might work}

The balloon dilatation technique has been employed for many years in cardiology and vascular surgery as a method of dilating narrowed vessels. The technique was modified and adopted by ENT surgeons for balloon sinuplasty in 2005, before being applied to the Eustachian tube in 2009. Although BET has been extensively used clinically in some countries, the inaccessibility of the Eustachian tube has limited investigation into the mechanism of the procedure. Little is known about the immediate effect of the balloon on soft tissues and any subsequent healing process.

The Eustachian tube opening is reported to appear widened after dilatation (Poe 2011b). In addition, an increase in the cross-sectional area of the Eustachian tube after dilatation has been reported on computed tomography (CT) imaging (Poe 2011a).

Cadaver studies have suggested that the mucosal lining of the Eustachian tube is crushed and the cartilage cracked during BET (MCCoul 2012a; Ockermann 2010; Poe 2011a). A single in vivo histological study reported that patients with Eustachian tube dysfunction had an abnormal, inflamed Eustachian tube lining prior to surgery, and biopsies taken immediately after BET demonstrated a diffuse crush injury and shearing of the superficial tissues (Kivekas 2015). In three cases, additional biopsies were obtained 5 to 12 weeks postoperatively, which showed restoration of largely uniformly healthy cells lining the Eustachian tube.

It has therefore been hypothesised that BET crushes unhealthy mucosa, promoting replacement with normal tissue. This correlates with visual findings in patients from uncontrolled series where surface inflammation was scored before BET and after a follow-up period (Poe 2011b; Silvola 2014). It is postulated that a wider opening and healthier cell lining after BET treatment might return the previously dysfunctional Eustachian tube to normal function.

\section{Why it is important to do this review}

Initial published data on BET have largely been limited to case series (Huisman 2018; Miller 2013; Randrup 2015), prohibiting firm conclusions regarding efficacy. Nevertheless, BET is already being adopted into clinical practice within many European countries, North America and Asia. In 2011, the UK National Institute for Health and Care Excellence (NICE) issued guidance on BET, concluding that evidence on procedure efficacy and safety was inadequate in quantity and quality (NICE 2011), and suggesting at the time that BET should only be performed in the research setting. Since this guidance further trials have been published including randomised controlled trials (Meyer 2018; Poe 2017).

\section{O B JECTIVES}

To evaluate the effects of balloon dilatation of the Eustachian tube in adults with obstructive Eustachian tube dysfunction.

\section{METHODS}

\section{Criteria for considering studies for this review Types of studies}

We will include studies with the following design characteristics:

- Randomised controlled trials.

We will include trials randomised both 'by patient' and 'by ear' providing, in the latter case, that the effects of treatment (both BET and the comparator) are measured using ear-specific outcome measures (e.g. tympanometry).

The Unit of analysis issues section provides further details on how data will be analysed if both split-person and between-person studies are included.

\section{Types of participants}

Individuals aged 18 years or older with chronic (more than three months duration) obstructive Eustachian tube dysfunction, as defined by the diagnostic criteria used by the trial investigators.

We will not exclude patients who have had previous medical or surgical treatment of Eustachian tube dysfunction. If paediatric cases have been included in a study, we will extract the adult data if participants were stratified by age prior to randomisation. If not, we will accept a level of 'contamination' with paediatric cases, as long as the adults make up more than $75 \%$ of the population.

We will exclude studies that include patients with:

- nasopharyngeal malignancy or excised malignancy obstructing the Eustachian tube;

- past radiation therapy to the head and neck;

- cleft palate or repaired cleft palate;

- craniofacial syndrome including Down syndrome;

- ciliary dysmotility syndrome.

\section{Types of interventions}

\section{Intervention}

Dilatation of the Eustachian tube by the inflation of a balloon of any size or pressure, by any surgical approach.

\section{Co-interventions}

BET may be performed at the same time as an additional otological or nasal procedure. If both intervention and comparator groups have been treated in the same way in this regard, we will include the study. Examples may include adenoidectomy, myringotomy and ventilation tube insertion. A study would also be included if the cointervention has no effect on Eustachian tube function; for example, suction clearance of the external ear for examination purposes.

\section{Comparisons}

The main comparisons will be: 
- BET versus no treatment;

- BET versus non-surgical treatment (medical and/or autoinflation devices).

Other comparison pairs will include:

- BET versus grommet (ventilation tube) insertion;

- BET versus laser tuboplasty.

\section{Types of outcome measures}

We will analyse the following outcomes in the review, but they will not be used as a basis for including or excluding studies.

We will extract data on outcomes according to the following time points: 0 to $<3$ months, 3 to $<12$ months, 12 to $<24$ months, 2 to 5 years.

\section{Primary outcomes}

- Obstructive Eustachian tube dysfunction symptoms - severity (patient-reported). This must be formally assessed using a validated questionnaire or scoring method (e.g. ETDQ-7; McCoul 2012b).

- Eustachian tube function measured by an objective or semi-objective test (e.g. sonotubometry, tubomanometry) (Smith 2015).

- Serious adverse events.

\section{Secondary outcomes}

- Hearing: changes in hearing thresholds from pre-intervention levels, measured in $\mathrm{dB} \mathrm{HL}$, using any conventional averaging method.

- Tympanic membrane abnormalities (e.g. presence of retraction pockets or perforations).

- Quality of life, as measured using a validated scoring system (e.g. EQ-5D, SF-36).

- Need for revision treatment.

- Other adverse events: including acute otitis media, or stenosed or patulous Eustachian tube.

\section{Search methods for identification of studies}

The Cochrane ENT Information Specialist will conduct systematic searches for randomised controlled trials and controlled clinical trials. There will be no language, publication year or publication status restrictions. We may contact original authors for clarification and further data if trial reports are unclear and we will arrange translations of papers where necessary.

\section{Electronic searches}

Published, unpublished and ongoing studies will be identified by searching the following databases from their inception:

- the Cochrane ENT Trials Register (search via the Cochrane Register of Studies to date);

- the Cochrane Central Register of Controlled Trials (CENTRAL) (search via the Cochrane Register of Studies to date);

- Ovid MEDLINE(R) Epub Ahead of Print, In-Process \& Other NonIndexed Citations, Ovid MEDLINE(R) Daily and Ovid MEDLINE(R) (1946 to date);

- Ovid Embase (1974 to date);
- LILACS (Latin American and Caribbean Health Science Information database; 1982 to date);

- Web of Knowledge, Web of Science (1945 to date);

- CNKI (searched via Google Scholar to date);

- ClinicalTrials.gov, www.clinicaltrials.gov (search via the Cochrane Register of Studies to date);

- World Health Organization (WHO) International Clinical Trials Registry Platform (ICTRP) (search to date).

The subject strategies for databases will be modelled on the search strategy designed for CENTRAL (Appendix 1). Where appropriate, these will be combined with subject strategy adaptations of the highly sensitive search strategy designed by Cochrane for identifying randomised controlled trials and controlled clinical trials (as described in the Cochrane Handbook for Systematic Reviews of Interventions Version 5.1.0, Box 6.4.b. (Handbook 2011)).

\section{Searching other resources}

We will scan the reference lists of identified publications for additional trials and contact trial authors if necessary. In addition, the Information Specialist will search Ovid MEDLINE, the Cochrane Library and Google to retrieve existing systematic reviews relevant to this systematic review, so that we can scan their reference lists for additional trials. The Information Specialist will also run non-systematic searches of Google Scholar to retrieve grey literature and other sources of potential trials.

We will not perform a separate search for adverse effects of balloon dilatation of the Eustachian tube for obstructive Eustachian tube dysfunction in adults. We will consider adverse effects described in the included studies only.

\section{Data collection and analysis}

\section{Selection of studies}

Two authors (AP and MS) will independently screen the titles and abstracts of every record identified in the search and indicate which reports should be retrieved. If there is insufficient information in the title and abstract to make such decisions, we will retrieve the full text. Two review authors (AP and MS) will independently read the full reports and determine whether these studies meet the inclusion criteria. We will resolve disagreements via discussion, or with a third review author as necessary. If resolving the disagreement is not possible, we will contact the authors for clarification. We will include an adapted PRISMA (Preferred Reporting Items for Systematic reviews and Meta-Analyses) flow chart of study selection (Liberati 2009).

\section{Data extraction and management}

For each included study, two review authors (AP and MS) will independently extract and record the following data using a piloted data collection form:

- Source: study, report and author ID, citation and contact details.

- Methods: study design, unit of randomisation, unit of analysis, total study duration, setting and follow-up.

- Participants: total number, setting, diagnostic criteria, age, sex, country, prior treatment, co-morbidity, socio-demographics; data on different presentations of Eustachian tube dysfunction (including presence of OME, tympanic membrane retraction, tympanic membrane perforation and cholesteatoma). We will 
also extract symptoms of Eustachian tube dysfunction without any abnormal signs.

- Interventions: total number of intervention groups, details of specific intervention (i.e. balloon size, inflation pressure and device design), prior medical or surgical interventions, any co-interventions. A recent systematic review found that no intervention has been demonstrated to be an effective treatment for Eustachian tube dysfunction (Llewellyn 2014), so we will group comparators in our analysis into medical and surgical treatments.

- Outcomes: outcome measures and time points (i) collected and (ii) reported, outcome definition, unit of measurement. We will categorise adverse events as early if occurring within 24 hours of the intervention or the start of medical treatment, or late if occurring more than 24 hours after. We will grade adverse events by severity according to the Clavien-Dindo system (Dindo 2004).

- Results: sample size, missing participants, summary data for each intervention group and subgroup analyses.

- Miscellaneous: funding, study author conflicts of interest, comments, correspondence required.

We will resolve disagreements via discussion or with a third review author as necessary. Where necessary, we will contact study investigators for clarification. We will extract adjusted or unadjusted results as guided by the Cochrane Handbook for Systematic Reviews of Interventions (Handbook 2011).

\section{Assessment of risk of bias in included studies}

Two review authors will undertake assessment of the risk of bias of the included trials independently, with the following taken into consideration, as guided by theCochrane Handbook (Handbook 2011):

- sequence generation;

- allocation concealment;

- blinding of participants and personnel;

- blinding of outcome assessment;

- incomplete outcome data;

- selective outcome reporting; and

- other sources of bias.

We will use the Cochrane 'Risk of bias' tool in RevMan 5.3 (RevMan 2014), which involves describing each of these domains as reported in the trial and then assigning a judgement about the adequacy of each entry: 'low', 'high' or 'unclear' risk of bias. We will resolve disagreements via discussion, or with a third review author as necessary.

We will account for baseline imbalances between groups when assessing selection bias according to the framework proposed by Corbett 2014 .

We will assess performance bias, detection bias and attrition bias for each of the review outcomes separately. We will report and group results as appropriate (for instance, by grouping self-reported and objective outcomes separately). We will summarise an overall risk of bias per outcome (Higgins 2011; Appendix 2).

We will assess risk of bias associated with the reliability of outcome measurement tools separately ('other bias' in the 'Risk of bias' tool) and account for this in the interpretation of the results.

\section{Measures of treatment effect}

We will express dichotomous data as a risk ratio (RR) with $95 \%$ confidence interval $(\mathrm{Cl})$. We will express continuous data (final values will be preferred over change scores) as a standardised mean difference (SMD) with $95 \% \mathrm{CI}$. If studies perform an ANCOVA analysis to account for a significant imbalance in outcome at baseline, then we will use these results. Where possible we will express time-to-event data (e.g. disease recurrence and re-treatment) as a hazard ratio. We will calculate unadjusted treatment effects using Cochrane's Review Manager (RevMan) software where possible (RevMan 2014).

\section{Unit of analysis issues}

We will take into account the level at which randomisation occurred. Unit of analysis issues may arise where the unit of randomisation differs from the unit of analysis. Trials may randomise participants to the interventions but report outcomes on a per-ear basis. Where the number of ears appears to equal the number of participants we will treat the ear as the unit of analysis. When this is not the case we will contact the study authors and request additional information to enable us to carry out a per-ear analysis, which takes into account the fact that some of the data may be non-independent. Pairing of data (within-patient) may arise where ears are both randomised and analysed. For such studies we will prefer adjusted results to account for within-person correlation and we will request additional information to enable us to calculate adjusted results from the study authors.

\section{Dealing with missing data}

Where necessary, we will contact the corresponding authors of included studies to supply any unreported data (such as group means and standard deviations (SDs), details of dropouts and details of interventions received by the control group). If a study reports outcomes only for participants completing the study or only for participants who followed the protocol, we will contact the authors and ask them to provide additional information to allow analyses according to intention-to-treat principles. We will describe missing data and dropouts/attrition for each included study in the 'Risk of bias' tables, and discuss the extent to which the missing data may affect the results and conclusions of the review. If data are still unavailable after author contact, we will use an available case analysis method, where data are included on only those whose results are known, using as a denominator the total number of people who had data recorded for the particular outcome in question. We will assess variation in the degree of missing data across studies as a potential source of heterogeneity.

We will assess the sensitivity of any primary meta-analyses to missing data using the method recommended by Higgins et al (Higgins 2008). We will report missing data per group.

\section{Assessment of heterogeneity}

We will assess clinical variation across studies by comparing the distribution of potentially important participant factors among trials (e.g. baseline severity, co-morbidities), and trial factors (randomisation concealment, blinding of outcome assessment, losses to follow-up, BET balloon size, inflation pressure, device type).

We will visually inspect the forest plots for heterogeneity by looking at the consistency of intervention effects across included studies. Where possible, we will describe statistical heterogeneity by computing the $\mathrm{I}^{2}$ statistic and $\mathrm{Chi}^{2}$ test. We will interpret the $\mathrm{I}^{2}$ and $\mathrm{Chi}^{2}$ 
values following the guidance in the Cochrane Handbook for Systematic Reviews of Interventions (Handbook 2011).

\section{Assessment of reporting biases}

If sufficient studies are found, we will assess reporting biases by visual inspection of funnel plots. Where possible, as a direct test for publication bias, we will compare results extracted from published journal reports with results obtained from other sources.

\section{Data synthesis}

Where appropriate, we will carry out all the analyses on an intention-to-treat basis. We will use RevMan 5.3 to carry out the metaanalyses for comparable trials and outcomes (RevMan 2014). We will perform statistical analyses according to the statistical guidelines referenced in the most recent version of the Cochrane Handbook for Systematic Reviews of Interventions (Handbook 2011). In the event of substantial clinical heterogeneity (for instance, significantly different presentations of Eustachian tube dysfunction) or methodological or statistical heterogeneity, we will not pool studies in a meta-analysis and we will present the results in a narrative summary. We will not pool split-person and between-person studies.

For some outcomes, such as Eustachian tube function test scores, symptoms scores and quality of life measures, different scales may be used, and some may be inverse to others. Where needed, we will standardise scales through multiplication or inversion, to allow comparison of results between methods.

We will look at all available data and, if data permit, combine and stratify studies according to intervention characteristics (for example, first- and second-line interventions, device and inflation characteristics). For continuous outcomes, we will prefer change scores over final values.

\section{Subgroup analysis and investigation of heterogeneity}

We will perform subgroup analysis based on:

- the different presentations of Eustachian tube dysfunction;

- the use of a planned co-intervention.

Presentation of Eustachian tube dysfunction can vary from symptoms of pressure to visible manifestations of chronic otitis media such as otitis media with effusion or cholesteatoma. We anticipate that study authors may select groups of patients with the same presentation in order to measure the effects of BET in an homogenous group.

If BET is used in combination with another intervention, for example, grommet insertion (and compared with grommet insertion alone) then that would also necessitate a subgroup analysis (measuring the effect of BET as an adjunct to grommet insertion). Large numbers of subgroup analyses may lead to misleading conclusions (Oxman 1992; Yusuf 1991), therefore these analyses will be exploratory and we will treat any conclusions with caution. Where possible we will investigate differences between two or more subgroups using the method described by Borenstein et al (Borenstein 2008).

\section{Sensitivity analysis}

We will perform sensitivity analysis to explore the influence of including only studies with an overall low risk of bias per outcome across all domains.

\section{GRADE and 'Summary of findings' table}

Two review authors (AP and MS) will independently use the GRADE approach to rate the overall certainty of evidence for each outcome using the GDT tool (http://www.guidelinedevelopment.org/).

The certainty of evidence reflects the extent to which we are confident that an estimate of effect is correct and we will apply this in the interpretation of results. There are four possible ratings: high, moderate, low and very low. A rating of high certainty of evidence implies that we are confident in our estimate of effect and that further research is very unlikely to change our confidence in the estimate of effect. A rating of very low certainty implies that any estimate of effect obtained is very uncertain.

The GRADE approach rates evidence from RCTs that do not have serious limitations as high certainty. However, several factors can lead to the downgrading of the evidence to moderate, low or very low. The degree of downgrading is determined by the seriousness of these factors:

- study limitations (risk of bias);

- inconsistency;

- indirectness of evidence;

- imprecision; and

- publication bias.

We will include a 'Summary of findings' table for the main comparisons listed (variations of 'BET versus conservative management'). This will be constructed according to the recommendations described in Chapters 10 and 11 of the Cochrane Handbook for Systematic Reviews of Interventions (Handbook 2011). Other comparisons, such as 'BET versus grommet insertion' will be tabulated separately. We will include the following primary outcomes:

- severity of patient-reported obstructive Eustachian tube dysfunction symptoms;

- Eustachian tube function measured by an objective or semi-objective test;

- adverse events (early and late).

Where possible, we will provide both relative and absolute measures of effect.

\section{ACKNOWLEDGEMENTS}

This project was supported by the National Institute for Health Research, via Cochrane Infrastructure, Cochrane Programme Grant or Cochrane Incentive funding to Cochrane ENT. The views and opinions expressed therein are those of the authors and do not necessarily reflect those of the Systematic Reviews Programme, NIHR, NHS or the Department of Health.

We are grateful to Naomi Shaw, Information Specialist with the Cochrane Wounds Group, for providing peer review comments on the draft search methods. 


\section{RE F E R E N C E S}

\section{Additional references}

\section{Adil 2014}

Adil E, Poe D. What is the full range of medical and surgical treatments available for patients with Eustachian tube dysfunction?. Current Opinion in Otolaryngology \& Head and Neck Surgery 2014;22(1):8-15.

\section{Alper 2012}

Alper CM, Swarts JD, Singla A, Banks J, Doyle WJ. Relationship between the electromyographic activity of the paratubal muscles and Eustachian tube opening assessed by sonotubometry and videoendoscopy. Archives of Otolaryngology -- Head and Neck Surgery 2012;138(8):741-6.

\section{Bluestone 2005}

Bluestone CD. Eustachian Tube. Structure, Function, Role in Otitis Media. New York: BC Decker, 2005.

\section{Borenstein 2008}

Borenstein M, Hedges LV, Higgins JPT, Rothstein HR. Introduction to Meta-analysis. Chichester (UK): John Wiley \& Sons, 2008.

\section{Browning 1992}

Browning GG, Gatehouse S. The prevalence of middle ear disease in the adult British population. Clinical Otolaryngology and Allied Sciences 1992;17(4):317-21.

\section{Catalano 2012}

Catalano PJ, Jonnalagadda S, Yu VM. Balloon catheter dilatation of Eustachian tube: a preliminary study. Otology \& Neurotology 2012;33(9):1549-52.

\section{Corbett 2014}

Corbett MS, Higgins JPT, Woolacott NF. Assessing baseline imbalance in randomised trials: implications for the Cochrane risk of bias tool. Research Synthesis Methods 2014;5(1):79-85.

\section{Dindo 2004}

Dindo D, Demartines N, Clavien PA. Classification of surgical complications: a new proposal with evaluation in a cohort of 6336 patients and results of a survey. Annals of Surgery 2004;240(2):205-21.

\section{Doyle 2013}

Doyle WJ, Swarts JD, Banks J, Casselbrant ML, Mandel EM, Alper CM. Sensitivity and specificity of Eustachian tube function tests in adults. JAMA Otolaryngology -- Head \& Neck Surgery 2013;139:719-27.

\section{Gürtler 2015}

Gürtler N, Husner A, Flurin H. Balloon dilation of the Eustachian tube. Otology \& Neurotology 2015;36(3):437-43.

\section{Handbook 2011}

Higgins JPT, Green S (editors). Cochrane Handbook for Systematic Reviews of Interventions Version 5.1.0 [updated
March 2011]. The Cochrane Collaboration, 2011. Available from www.cochrane-handbook.org.

\section{Higgins 2008}

Higgins JPT, White IR, Wood AM. Imputation methods for missing outcome data in meta-analysis of clinical trials. Clinical Trials 2008;5(3):225-39.

\section{Higgins 2011}

Higgins JP, Altman DG, Gøtzsche PC, Jüni P, Moher D, Oxman AD, et al. Cochrane Bias Methods Group, Cochrane Statistical Methods Group. The Cochrane Collaboration's tool for assessing risk of bias in randomised trials. BMJ 2011;343:d5928.

\section{Huisman 2018}

Huisman JML, Verdam FJ, Stegeman I, de Ru JA. Treatment of Eustachian tube dysfunction with balloon dilation: a systematic review. Laryngoscope 2018;128(1):237-47. [DOI: 10.1002/ lary.26800]

\section{Jerger 1972}

Jerger J, Jerger S, Mauldin L. Studies in impedance audiometry. I. Normal and sensorineural ears. Archives of Otolaryngology 1972;96(6):513-23

\section{Kivekas 2015}

Kivekas I, Chao WC, Faquin W, Hollowell M, Silvola J, Rasooly T, et al. Histopathology of balloon-dilation Eustachian tuboplasty. Laryngoscope 2015;125(2):436-41.

\section{Liberati 2009}

Liberati A, Altman DG, Tetzlaff J, Mulrow C, Gøtzsche PC, Ioannidis JP, et al. The PRISMA statement for reporting systematic reviews and meta-analyses of studies that evaluate health care interventions: explanation and elaboration. Journal of Clinical Epidemiology 2009;62(10):e1-34.

\section{Llewellyn 2014}

Llewellyn A, Norman G, Harden M, Coatesworth A, Kimberling D, Schilder A, et al. Interventions for adult Eustachian tube dysfunction: a systematic review. Health Technology Assessment 2014;18(46):1-180, v-vi. [DOI: 10.3310/hta18460]

\section{McCoul 2012a}

McCoul ED, Singh A, Anand VK, Tabaee A. Balloon dilation of the Eustachian tube in a cadaver model: technical considerations, learning curve, and potential barriers. Laryngoscope 2012;122(4):718-23.

\section{McCoul 2012b}

McCoul ED, Anand VK, Christos PJ. Validating the clinical assessment of Eustachian tube dysfunction: The Eustachian Tube Dysfunction Questionnaire (ETDQ-7). Laryngoscope 2012;122(5):1137-41.

\section{McCoul 2012c}

McCoul ED, Anand VK. Eustachian tube balloon dilation surgery. International Forum of Allergy \& Rhinology 2012;2(3):191-8. 


\section{Meyer 2018}

Meyer TA, O'Malley EM, Schlosser RJ, Soler ZM, Cai J, Hoy MJ, et al. A randomized controlled trial of balloon dilation as a treatment for persistent Eustachian tube dysfunction with 1year follow-up. Otology \& Neurotology 2018;39(7):894-902.

\section{Miller 2013}

Miller BJ, Elhassan HA. Balloon dilatation of the Eustachian tube: an evidence based review of case series for those considering its use. Clinical Otolaryngology 2013;38(6):525-32.

\section{NICE 2011}

National Institute for Health and Care Excellence. Balloon dilatation of the Eustachian tube: NICE interventional procedure guidance 409. London: National Institute for Health and Care Excellence, 2011.

\section{Ockermann 2010}

Ockermann T, Reineke U, Upile T, Ebmeyer J, Sudhoff HH. Balloon dilation Eustachian tuboplasty: a feasibility study. Otology \& Neurotology 2010;31(7):1100-3.

\section{Oxman 1992}

Oxman AD, Guyatt GH. A consumers guide to subgroup analyses. Annals of Internal Medicine 1992;116:78-84.

\section{Pau 2009}

Pau HW, Sievert U, Just T, Sade J. Pressure changes in the human middle ear without opening the Eustachian tube. Acta Oto-Laryngologica 2009;129(11):1182-6.

\section{Perera 2013}

Perera R, Glasziou PP, Heneghan CJ, McLellan J, Williamson I. Autoinflation for hearing loss associated with otitis media with effusion. Cochrane Database of Systematic Reviews 2013, Issue 5. [DOI: 10.1002/14651858.CD006285.pub2]

\section{Poe 2000}

Poe D, Pyykkö I, Valtonen H, Silvola J. Analysis of Eustachian tube function by video endoscopy. American Journal of Otology 2000;21(5):602-7.

\section{Poe 2011a}

Poe DS, Hanna BM. Balloon dilation of the cartilaginous portion of the Eustachian tube: initial safety and feasibility analysis in a cadaver model. American Journal of Otology 2011;32(2):115-23.

\section{Poe 2011b}

Poe DS, Silvola J, Pyykko I. Balloon dilation of the cartilaginous Eustachian tube. Otolaryngology - Head and Neck Surgery 2011;144(4):563-9.

\section{Poe 2017}

Poe D, Anand V, Dean M, Roberts WH, Stolovitzky JP, Hoffmann K, et al. Balloon dilation of the Eustachian tube for dilatory dysfunction: a randomized controlled trial. Laryngoscope 2017 Sep 20 [Epub ahead of print]. [DOI: 10.1002/ lary.26827]

\section{Randrup 2015}

Randrup TS, Ovesen T. Balloon Eustachian tuboplasty: a systematic review. Otolaryngology - Head and Neck Surgery 2015;152(3):383-92.

\section{RevMan 2014 [Computer program]}

The Nordic Cochrane Centre, The Cochrane Collaboration. Review Manager (RevMan). Version 5.3. Copenhagen: The Nordic Cochrane Centre, The Cochrane Collaboration, 2014.

\section{Sade 1997}

Sade J, Ar A. Middle ear and auditory tube: middle ear clearance, gas exchange, and pressure regulation. Otolaryngology - Head and Neck Surgery 1997;116(4):499-524.

\section{Schilder 2015}

Schilder AGM, Bhutta MF, Butler CC, Holy C, Levine LH, Kvaerner KJ, et al. Eustachian tube dysfunction: consensus statement on definition, types, clinical presentation and diagnosis. Personal communication to G Norman 2015.

\section{Schroder 2015}

Schröder S, Lehmann M, Ebmeyer J, Upile T, Sudhoff H. Balloon Eustachian tuboplasty: a retrospective cohort study. Clinical Otolaryngology 2015;40(6):629-38.

\section{Silvola 2014}

Silvola J, Kivekäs I, Poe DS. Balloon dilation of the cartilaginous portion of the Eustachian tube. Otolaryngology - Head and Neck Surgery 2014;151(1):125-30.

\section{Smith 2015}

Smith ME, Tysome JR. Tests of Eustachian tube function: a review. Clinical Otolaryngology 2015;40(4):300-11.

\section{Smith 2018}

Smith ME, Takwoingi Y, Deeks J, Alper C, Bance ML, Bhutta MF, et al. Eustachian tube dysfunction: a diagnostic accuracy study and proposed diagnostic pathway. PloS One 2018;13(11):e0206946.

\section{Vila 2017}

Vila PM, Thomas T, Liu C, Poe D, Shin JJ. The burden and epidemiology of Eustachian tube dysfunction in adults. Otolaryngology - Head and Neck Surgery 2017;156(2):278-84.

\section{Yusuf 1991}

Yusuf S, Wittes J, Probsfield K, Tyroler HA. Analysis and interpretation of treatment effects in subgroups of patients in randomized clinical trials. JAMA 1991;266:93-8.

\section{APPENDICES}

\section{Appendix 1. CENTRAL search strategy}

1 MESH DESCRIPTOR Eustachian Tube EXPLODE ALL AND CENTRAL:TARGET 
2 ((eustachian or auditory or pharyngotympanic) next tube*):AB,EH,KW,KY,MC,MH,TI,TO AND CENTRAL:TARGET

3 (eustachian next (dysfunction OR canal or orifice*)):AB,EH,KW,KY,MC,MH,TI,TO AND CENTRAL:TARGET0

4 (middle next ear adj3 dysfunction*):AB,EH,KW,KY,MC,MH,TI,TO AND CENTRAL:TARGET

5 \#1 OR \#2 OR \#3 OR \#4 AND CENTRAL:TARGET

6 (balloon* and (dilation or dilated or Dilatation or catheter* or transtympanic or tubuloplast* or tuboplast*)):AB,EH,KW,KY,MC,MH,TI,TO AND CENTRAL:TARGET

7 ((eustachian or endonasal or transtympanic or (middle next ear)) and (dilation or dilated or Dilatation or tubuloplast* or catheter ${ }^{\star}$ or tuboplast*)):AB,EH,KW,KY,MC,MH,TI,TO AND CENTRAL:TARGET

8 EET or BDET or Bielefeld or AERA or BET or tubavent or XprESS or jarit or miltex or ETBD or integra AND CENTRAL:TARGET

9 MESH DESCRIPTOR Dilatation EXPLODE ALL AND CENTRAL:TARGET

10 MESH DESCRIPTOR Catheterization AND CENTRAL:TARGET

11 \#6 OR \#7 OR \#8 OR \#9 OR \#10 AND CENTRAL:TARGET

12 \#5 AND \#11 AND CENTRAL:TARGET

13 MESH DESCRIPTOR Eustachian Tube EXPLODE ALL WITH QUALIFIER SU AND CENTRAL:TARGET

14 \#12 OR \#13 AND CENTRAL:TARGET

\section{Appendix 2. Assessment of risk of bias}

\section{Was the allocation sequence randomly generated?}

\section{Low risk of bias}

The investigators describe a random component in the sequence generation process such as: referring to a random number table; using a computer random-number generator; coin tossing; shuffling cards or envelopes; throwing dice; drawing of lots.

\section{High risk of bias}

The investigators describe a non-random component in the sequence generation process. Usually, the description would involve some systematic, non-random approach, for example: sequence generated by odd or even date of birth; sequence generated by some rule based on date (or day) of admission; sequence generated by some rule based on hospital or clinic record number.

\section{Unclear}

Insufficient information about the sequence generation process provided to permit a judgement of low or high risk of bias.

\section{Was the treatment allocation adequately concealed?}

\section{Low risk of bias}

Participants and investigators enrolling participants could not foresee assignment because one of the following, or an equivalent method, was used to conceal allocation: central allocation (including telephone, web-based and pharmacy-controlled randomisation); sequentially-numbered drug containers of identical appearance; sequentially-numbered, opaque, sealed envelopes.

\section{High risk of bias}

Participants or investigators enrolling participants could possibly foresee assignments and thus introduce selection bias, such as allocation based on: using an open random allocation schedule (e.g. a list of random numbers); assignment envelopes were used without appropriate safeguards (e.g. if envelopes were unsealed or non opaque or not sequentially-numbered); alternation or rotation; date of birth; case record number; any other explicitly unconcealed procedure.

\section{Unclear}

Insufficient information provided to permit a judgement of low or high risk of bias. This is usually the case if the method of concealment is not described or not described in sufficient detail to allow a definite judgement, for example if the use of assignment envelopes is described, but it remains unclear whether envelopes were sequentially numbered, opaque and sealed.

\section{Blinding - was knowledge of the allocated interventions adequately prevented during the study?}

\section{Low risk of bias}

Any one of the following.

- No blinding, but the review authors judge that the outcome and the outcome measurement are not likely to be influenced by lack of blinding.

- Blinding of participants and key study personnel ensured, and unlikely that the blinding could have been broken. 
- Either participants or some key study personnel were not blinded, but outcome assessment was blinded and the non-blinding of others was unlikely to introduce bias.

\section{High risk of bias}

Any one of the following.

- No blinding or incomplete blinding, and the outcome or outcome measurement is likely to be influenced by lack of blinding.

- Blinding of key study participants and personnel attempted, but likely that the blinding could have been broken and the outcome or outcome measurement is likely to be influenced by lack of blinding.

- Either participants or some key study personnel were not blinded, and the non-blinding was likely to introduce bias.

\section{Unclear}

Either of the following.

- Insufficient information provided to permit a judgement of low or high risk of bias.

- The study did not address this outcome.

\section{Were incomplete outcome data adequately addressed?}

\section{Low risk of bias}

Any one of the following.

- No missing outcome data.

- Reasons for missing outcome data unlikely to be related to true outcome (for survival data, censoring unlikely to be introducing bias).

- Missing outcome data balanced in numbers across intervention groups, with similar reasons for missing data across groups.

- For dichotomous outcome data, the proportion of missing outcomes compared with observed event risk was not enough to have a clinically relevant impact on the intervention effect estimate.

- For continuous outcome data, plausible effect size (difference in means or standardised difference in means) among missing outcomes was not enough to have a clinically relevant impact on observed effect size.

- Missing data have been imputed using appropriate methods.

\section{High risk of bias}

Any one of the following.

- Reason for missing outcome data likely to be related to true outcome, with either imbalance in numbers or reasons for missing data across intervention groups.

- For dichotomous outcome data, the proportion of missing outcomes compared with observed event risk was enough to induce clinically relevant bias in intervention effect estimate.

- For continuous outcome data, plausible effect size (difference in means or standardised difference in means) among missing outcomes was enough to induce clinically relevant bias in observed effect size.

- 'As-treated' analysis done with substantial departure of the intervention received from that assigned at randomisation.

- Potentially inappropriate application of simple imputation.

\section{Unclear}

Either of the following.

- Insufficient reporting of attrition/exclusions to permit a judgement of low or high risk of bias (e.g. number randomised not stated, no reasons for missing data provided).

- The study did not address this outcome.

\section{Are reports of the study free of suggestion of selective outcome reporting?}

\section{Low risk of bias}

Either of the following.

- The study protocol is available and all of the study's pre-specified (primary and secondary) outcomes that are of interest in the review have been reported in the pre-specified way. 
- The study protocol is not available but it is clear that the published reports include all expected outcomes, including those that were pre-specified (convincing text of this nature may be uncommon).

\section{High risk of bias}

Any one of the following.

- Not all of the study's pre-specified primary outcomes have been reported.

- One or more primary outcomes are reported using measurements, analysis methods or subsets of the data (e.g. subscales) that were not pre-specified.

- One or more reported primary outcomes of the study were not pre-specified (unless clear justification for their reporting is provided, such as an unexpected adverse effect).

- One or more outcomes of interest in the review are reported incompletely so that they cannot be entered in a meta-analysis.

- The study report fails to include results for a key outcome that would be expected to have been reported for such a study.

\section{Unclear}

Insufficient information provided to permit judgement of low or high risk of bias. It is likely that the majority of studies will fall into this category.

\section{Other sources of potential bias}

\section{Low risk of bias}

The study appears to be free of other sources of bias.

\section{High risk of bias}

There is at least one important additional risk of bias. For example, the study:

- had a potential source of bias related to the specific study design used; or

- has been claimed to have been fraudulent; or

- used non-or poorly validated outcome measures; or

- had significant baseline imbalances present for important prognostic variable(s) and had randomisation and/or allocation concealment methods that were inadequate or unclear, or had no baseline details and had randomisation and/or allocation concealment methods that were inadequate (Corbett 2014);

- had some other problem.

\section{Unclear}

There may be a risk of bias, but there is either:

- insufficient information to assess whether an important risk of bias exists; or

- insufficient rationale or evidence that an identified problem will introduce bias.

\section{CONTRIBUTIONS OF AUTHORS}

Anant Patel: drafting of protocol, data extraction and analysis, first author of manuscript.

Matthew E Smith: drafting of protocol, data extraction and analysis, editing of manuscript.

Gill Norman: editorial support at all stages.

Alexis Llewellyn: editorial support at all stages.

James R Tysome: editorial support at all stages.

\section{DECLARATIONS OF INTEREST}

Anant Patel: none known.

Matthew E Smith: Matthew Smith was trained in the BET technique in Bielefeld, Germany, with trip expenses covered by Spiggle and Theis GmbH (October 2014). 
Gill Norman: Gill Norman attended a diagnostic consensus meeting funded by Acclarent (a BET device manufacturer \& Johnson and Johnson subsidiary) in June 2014, but she received no financial compensation and expenses were met by the University of York.

Alexis Llewellyn: none known.

James R Tysome: James Tysome has received a research grant from Spiggle and Theis $\mathrm{GmbH}$, an instrument manufacturing company who market a BET device (2015). The grant was not provided for this review and the company have no influence on its creation.

\section{SOURCES OF SUPPORT}

\section{Internal sources}

- No sources of support supplied

\section{External sources}

- National Institute for Health Research, UK.

Infrastructure funding for Cochrane ENT 